\title{
Does the 'Liverpool Care Pathway' facilitate an improvement in quality of care for dying cancer patients?
}

\author{
C R Mayland ${ }^{*}, 1$ E M I Williams ${ }^{2}$, J Addington-Hall ${ }^{3}$, T F Cox ${ }^{4}$ and J E Ellershaw ${ }^{4}$
}

${ }^{1}$ Marie Curie Palliative Care Institute Liverpool (MCPCIL), University of Liverpool, Liverpool, L3 9TA, UK; ${ }^{2}$ Department of Public Health and Policy, University of Liverpool, Liverpool, L69 3BX, UK; ${ }^{3}$ Faculty of Health Sciences, University of Southampton, Southampton, SO17 1BJ, UK and ${ }^{4}$ Cancer Research UK Liverpool Cancer Trials Unit, University of Liverpool, Liverpool, L69 3GL, UK

Background: The Liverpool Care Pathway for the Dying Patient (LCP) aims to transfer hospice principles of care for dying patients to other health-care sectors. This post-bereavement survey explored the LCP's effectiveness in improving quality of care for cancer patients.

Methods: Postal self-completion questionnaires were sent to 778 next-of-kin to consecutive deceased patients who had died an 'expected' cancer death in a hospice and acute tertiary hospital.

Results: Following exclusions $(n=53), 255$ of the 725 next-of-kin agreed to participate (35.2\% response rate). Overall hospice participants reported the best quality of care, and hospital participants, for whom care was not supported by the LCP, reported the worst quality of care. Multivariate analysis showed the hospice was an independent predictor for patients being treated with dignity (OR 8.46) and receiving adequate family support (OR 7.18) $(P<0.0001)$. Care supported by the LCP and the hospital specialist palliative care team were both associated with good family support, but neither was an independent predictor.

Conclusions: From the bereaved relatives' perspective, within the hospital, the LCP is effective in improving specific aspects of care, such as symptom control for dying patients. Further improvement is required, however, to attain the hospice standard of care.

Recent end-of-life care policies at both national and international level have focused on enabling more people to die in their preferred place of care, which generally is at home (Department of Health, 2008a; Commonwealth of Australia, 2010). Although patients with terminal cancer can have a more predictable disease trajectory compared with non-malignant illnesses, difficulties in accurate prognostication mean a significant proportion of cancer patients will continue to die in the acute hospital (Dunlop et al, 1989; Auret et al, 2003). Although a small but steady increase in the proportion of home deaths (from 18.3 to 20.8\%) occurred within the United Kingdom between 2004 and 2010 (Gomes et al, 2011a), the majority of patients within many developed countries, including the United Kingdom, continue to die in hospitals (Costantini et al, 2000; Yang et al, 2006; Gomes and Higginson, 2008b).

Evidence over the last 30 years has demonstrated many shortcomings in the provision of care for dying cancer patients within the acute sector (Field, 1989; Mills et al, 1994; AddingtonHall and O'Callaghan, 2009). Basic principles of palliative care have not always been practised, often resulting in insufficient symptom control, poor communication and inadequate psychological support for patients and their families (Ellershaw et al, 1997a). One initiative introduced to try to improve care for the dying was the Liverpool Care Pathway for the Dying Patient (LCP) (Ellershaw and Wilkinson, 2011b). The LCP is an integrated care 
pathway that aims to transfer the principles of hospice care, generally regarded as the standard of excellence, into other settings in a format familiar to the main stream health-care system. The LCP was recommended in a recent national UK policy initiative, 'The Route to Success in end-of-life care in acute hospitals', (National End of Life Care Programme, 2010) specifically linked with the End-of-life Care Strategy (Department of Health, 2008a), and was also highlighted within the General Medical Council (GMC) guidance as a document to help facilitate decision-making and support care for those who are in the last days of their life (General Medical Council, 2010). Recently, however, criticism and potential misrepresentation of the LCP has featured heavily within the UK media.

Previous work demonstrated that UK health-care professionals perceive the LCP to have a positive impact on patients and families, and help improve staff confidence levels when caring for dying patients (Jack et al, 2003). Similar findings were seen in a recent New Zealand study where the LCP was introduced in two acute hospital wards; staff perceived that the LCP had a positive benefit on end-of-life care, assisting with decision-making, communication and symptom control (Clerk et al, 2012). Results from a preand post-comparison LCP study in the Netherlands have indicated that from the bereaved relatives' perspective, symptom control and some aspects of communication are improved (Veerbeek et al, 2008). Further testing of the LCP's effectiveness in improving care and support for dying patients and their families from the user perspective has not been undertaken within the United Kingdom. In order to assess the effectiveness of the LCP in transferring hospice care into the acute sector, the primary aim of this study was to compare bereaved relatives' perspectives about the quality of care in the last days of life for all 'expected' cancer deaths in a UK hospice and acute hospital currently using the LCP. In particular, two key outcome measures were assessed: whether the patient was treated with dignity and respect, and whether the family was adequately supported.

\section{MATERIALS AND METHODS}

A post-bereavement survey was conducted with next-of-kin to cancer patients who had died within the chosen hospice or acute tertiary hospital in Liverpool. All consecutive patients who had died within a 21-month period (during 2005 or 2006) were included according to the following eligibility criteria:

(i) over 18 years of age;

(ii) had an 'expected death' defined as either having their care supported by the LCP (version 11) or had a 'Not for resuscitation' decision documented, and the cause of death on the death certificate was not sudden in nature.

Database records of all the deaths and patients' next-of-kin were cross-referenced against the LCP database, the Patient Administration database (within the hospice) and a Bereavement database (within the hospital); the latter records whether or not the patient's care was supported by the LCP and the resuscitation decision made by the patients' responsible medical team. Manual checking of hospice case records and hospital bereavement records (stating cause of death on the death certificates) was undertaken to exclude sudden or unexpected deaths (Supplementary Figure 1) by the primary researcher $(\mathrm{CM})$, and any uncertainties were discussed with a second researcher (JE).

Sample size was calculated using a previous post-bereavement study with 'Views Of Informal Carers - Evaluation of Services' (VOICES) questionnaire, which showed that 97\% bereaved relatives perceived that their family member was treated with dignity 'always' or 'most of the time' in the hospice, compared with
$70 \%$ for those in the hospital (Addington-Hall and O'Callaghan, 2009). We hypothesised that $95 \%$ of relatives would perceive that patients were treated with dignity in the hospice and $80 \%$ in the hospital. Using $5 \%$ significance level and $90 \%$ power, a sample size of $\sim 100$ relatives was needed from each setting (hospice and hospital). By estimating a response rate of $40 \%$, the total sample size required was at least 500 participants.

An information pack including the questionnaire, 'Evaluating Care and Health Outcomes - for the Dying' (ECHO-D) was sent out to 778 next-of-kins during 2006, at least 3 months following the bereavement. ECHO-D consists of 91 items, was developed from the goals of the LCP document, the existing post-bereavement surveys (including VOICES) and aspects of a 'good death' determined from the literature, and has been shown to be valid and reliable (Mayland, 2010; Mayland et al, 2012b). Reminder letters were sent out 4 weeks after the first mailing to non-respondents. Ethical approval was obtained from Liverpool (Adult) Ethics Committee (05/Q1505/126).

Data were analysed using SPSS version 16 and Statistical Analysis System (SAS) version 9.2 (University of Liverpool, Liverpool, UK). Comparisons of demographic data used $\chi^{2}$ tests, independent sample $t$-testing and Mann-Whitney $U$-testing. Comparisons between questionnaire responses used the Pearson's $\chi^{2}$ statistic with $95 \%$ confidence intervals. For questions with ordinal response options, the Cochran-Mantel-Haenszel test was conducted using standardized mid-rank scores. Forced entry logistic regression was conducted to determine whether any demographic differences independently predicted responses to two key outcome measures: whether the patient was treated with dignity and respect, and whether the family was adequately supported.

\section{RESULTS}

Of the 778 eligible to participate patients, 52 were excluded (nextof-kin had either died $(n=3)$ or moved house $(n=49)$ with no forwarding contact details). This left 726 potential participants, of whom 255 agreed to participate (35.1\% response rate). Response rate was higher for the hospice next-of-kin compared with the hospital group (40.5\% (109 of 269) vs 31.9\% (146 of 457) $\chi^{2} 5.46$, $P=0.02)$. An additional $141(18.1 \%)$ returned their response forms, but declined participation, citing 'emotional distress' as the most common reason. Non-participants had a higher proportion of 'other (for example, unknown primary)' as the patient's primary site of cancer compared with participants $(n=128$ (27.2\%) vs $n=42$ (16.5\%), $\left.\chi^{2} 10.57, P<0.001\right)$ (Supplementary Table 6). All patients who died an 'expected death' in the hospice were cared for by the LCP, with the others $(n=73)$ having a more acute decline due to complications from their illness or being unable to retrieve case notes to clarify details. Within the hospital, for those who completed the ECHO-D questionnaire, 78 (53.4\%) deceased patients had their care supported by the LCP ('Hospital with LCP' group) and 68 (46.6\%) did not ('Hospital without LCP' group).

For participants, demographic details of deceased patients and their next-of-kin were compared (Table 1 and Supplementary Table 7). Deceased hospice patients, compared with hospital patients, were younger ( 68.5 vs 72.3 years, $P=0.02)$, more likely to be female $(57.8 \%$ vs $45.9 \%, P=0.05)$ and more likely to have breast cancer $(12.8 \%$ vs $3.4 \%, P=0.005)$. Deceased 'Hospital with LCP' patients, compared with deceased 'Hospital without LCP' patients (Table 1$)$, were older (74.6 vs 69.6 years, $P=0.02)$ and more likely to have had hospital specialist palliative care team (HSPCT) involvement $(44.9 \%$ vs $28.4 \%, P=0.04)$. The median time since bereavement was significantly shorter for the 'Hospital with LCP' participants (276.0 days) compared with 'Hospital without LCP' participants (415.5 days) ( $U$ 1628.5, $P<0.0001)$. 
Table 1. Comparison of demographic details for deceased patients and their next-of-kin for the different participant groups ${ }^{\mathrm{a}}$

\begin{tabular}{|c|c|c|c|c|c|c|}
\hline & $\begin{array}{l}\text { Hospice } \\
(n=109)\end{array}$ & $\begin{array}{l}\text { All hospital } \\
(n=146)\end{array}$ & $P$-value & $\begin{array}{l}\text { Hospital }+ \text { LCP } \\
(n=78)^{\mathrm{b}}\end{array}$ & $\begin{array}{l}\text { Hospital - LCP } \\
\quad(n=68)\end{array}$ & $P$-value \\
\hline Deceased patient & \multicolumn{2}{|c|}{$\begin{array}{l}\text { Mean } \pm \text { s.d. or number (\%) } \\
\text { or median (IQR) }\end{array}$} & \multicolumn{4}{|c|}{$\begin{array}{l}\text { Mean } \pm \text { s.d. or number }(\%) \\
\quad \text { or median (IQR) }\end{array}$} \\
\hline Age (years) & $68.5 \pm 12.9$ & $72.3 \pm 12.5$ & 0.02 & $74.6 \pm 10.9$ & $69.6 \pm 13.7$ & 0.02 \\
\hline Number of females & $63(57.8)$ & $67(45.9)$ & 0.05 & $38(48.7)$ & $30(44.1)$ & NS \\
\hline $\begin{array}{l}\text { Median length of final admission } \\
\text { (days) }\end{array}$ & $15(6.5-28.0)$ & $11.5(4.75-25.0)$ & NS & $12.0(5.75-23.0)$ & $10.0(4.0-27.0)$ & NS \\
\hline \multicolumn{7}{|l|}{ Primary site of cancer } \\
\hline $\begin{array}{l}\text { Lung } \\
\text { Colorectal } \\
\text { Oesophagus } \\
\text { Stomach } \\
\text { Pancreas } \\
\text { Bladder } \\
\text { Non-Hodgkin's lymphoma } \\
\text { Leukaemia } \\
\text { Prostate } \\
\text { Breast } \\
\text { Ovary } \\
\text { Other } \\
\text { HSPCT }^{c} \text { involvement }\end{array}$ & $\begin{array}{c}32(29.4) \\
12(11.0) \\
10(9.2) \\
6(5.5) \\
5(4.6) \\
3(2.8) \\
0(0.0) \\
0(0.0) \\
5(4.6) \\
14(12.8) \\
5(4.6) \\
17(15.6) \\
\text { NA }\end{array}$ & $\begin{aligned} 29 & (19.9) \\
14 & (9.6) \\
6 & (4.1) \\
7 & (4.8) \\
19 & (13.0) \\
8 & (5.5) \\
5 & (3.4) \\
13 & (8.9) \\
11 & (7.5) \\
5 & (3.4) \\
3 & (2.1) \\
25 & (17.1) \\
& \text { NA }\end{aligned}$ & $\begin{array}{l}\text { NS } \\
\text { NS } \\
\text { NS } \\
\text { NS } \\
0.02 \\
\text { NS } \\
0.06 \\
0.001 \\
\text { NS } \\
0.005 \\
\text { NS } \\
\text { NS } \\
\text { NA }\end{array}$ & $\begin{array}{c}17(21.8) \\
8(10.2) \\
5(6.4) \\
3(3.8) \\
11(14.1) \\
5(6.4) \\
3(3.8) \\
4(5.1) \\
6(7.7) \\
1(1.3) \\
3(3.8) \\
12(15.4) \\
35(44.9)\end{array}$ & $\begin{array}{c}12(17.6) \\
6(8.8) \\
1(1.5) \\
4(5.9) \\
8(11.8) \\
3(4.4) \\
2(2.9) \\
9(13.2) \\
5(7.4) \\
4(5.9) \\
0(0.0) \\
14(20.6) \\
19(28.4)\end{array}$ & $\begin{array}{l}\text { NS } \\
\text { NS } \\
\text { NS } \\
\text { NS } \\
\text { NS } \\
\text { NS } \\
\text { NS } \\
\text { NS } \\
\text { NS } \\
\text { NS } \\
\text { NS } \\
\text { NS } \\
0.04\end{array}$ \\
\hline \multicolumn{7}{|l|}{ Next-of-kin (participant) } \\
\hline Number of female participants & $70(64.2)$ & $93(63.7)$ & NS & $46(59.0)$ & $43(63.2)$ & NS \\
\hline $\begin{array}{l}\text { Median time since bereavement } \\
\text { (days) }\end{array}$ & $341(221-486)$ & 324.5 (194-497) & NS & $276.0(167-446.8)$ & $415.5(266-541.8)$ & $<0.0001$ \\
\hline \multicolumn{7}{|c|}{$\begin{array}{l}{ }^{a} \text { Comparisons between groups were made using the independent sample t-testing for continuous parametric data, Pearson's } \chi^{2} \text { statistic for categorical data (Fisher's exact test if expected } \\
\text { frequencies were less than five), and Mann-Whitney } U \text { for continuous non-parametric data. } \\
b^{\prime} \text { Hospital }+L C P^{\prime}=\text { patient's care was supported by the } L C P \text { before death; 'hospital }-L C P^{\prime}=\text { patient's care was not supported by the } L C P \text { before death. } \\
{ }^{{ }_{H} H S P C T}=\text { hospital specialist palliative care team; } N S=\text { nonsignificant }(P>0.05) \text {. Bold values indicate the statistically significant results. }\end{array}$} \\
\hline
\end{tabular}

Symptom control. With the exception of retained respiratory tract secretions, the 'Hospital without LCP' participants reported the highest symptom burden for their next-of-kin (Table 2). Hospice participants were most likely to be satisfied and the 'Hospital without LCP' participants least likely to be satisfied with the level of symptom control (Table 2). The level of satisfaction for 'Hospital with LCP' participants' was between these two levels. For example, seventy-eight (72.2\%) hospice participants responded that doctors and nurses had done enough to relieve the pain 'all of the time' compared with 46 (59.0\%) 'Hospital with LCP' participants and $23(33.8 \%)$ 'Hospital without LCP' participants $(P<0.0001)$. Similar differences were seen for the control of restlessness and breathlessness.

Communication. Responses indicated that more open discussion about the provision and withdrawal of fluids in both health-care settings was needed, but especially in the acute hospital (Hospice $n=20,18.3 \%$, 'Hospital with LCP' $n=33,42.3 \%$, 'Hospital without LCP' $n=33,48.5 \%, p=0.003$ ) (Table 3). Discussions informing participants that their family member was likely to die occurred on a similar frequency in both health-care settings (Hospice $n=83,76.9 \%$, 'Hospital with LCP' $n=61,78.2 \%$, 'Hospital without LCP' $n=46,67.6 \% ; P=\mathrm{NS}$ ) and generally were of good quality. More hospice participants $(n=44,40.4 \%)$ reported conversations with health-care professionals about what to expect when their loved one died compared with the 'Hospital with LCP' $(n=22,28.8 \%)$ and 'Hospital without LCP' ( $n=11$, $16.2 \%)$ participants $(P=0.002)$.
Key outcomes - dignity and respect, and family support. Univariate analysis showed that the only variable associated with patients 'always' being treated with dignity and respect was when they received hospice care (OR 8.46, $P<0.0001)$ (Table 4). Similarly, participants perceived that they were adequately supported when care was provided by the hospice (OR 7.18, $P<0.0001$ ) (Table 5). Participants within the hospital perceived that they were adequately supported when care was supported by the LCP $(P=0.04)$ and when the HSPCT were involved $(P=0.04)$, although multivariate analysis showed that neither was an independent predictor (LCP $P=0.08$; HSPCT $P=0.09$ ) (Supplementary Table 8).

\section{DISCUSSION}

To our knowledge, this is the first post-bereavement study within the United Kingdom that explores the impact of the LCP on the quality of care for dying cancer patients from the user's perspective. Overall, hospice participants reported the highest quality of care for dying patients and their families, and the 'Hospital without LCP' participants reported the lowest quality of care. The quality of care reported by the 'Hospital with LCP' participants was reported as being in between these two levels. The overall aim and philosophy of the LCP is to transfer the principles and 'best practice' of hospice care into the acute hospital setting. This study demonstrates that for some aspects of care, such as symptom control, this cultural shift appears to be occurring, 
Table 2. Symptom control: comparison of bereaved relatives' views in the hospice as opposed to the hospital ${ }^{\text {a }}$

\begin{tabular}{|c|c|c|c|c|c|c|c|c|c|}
\hline \multicolumn{3}{|c|}{$\begin{array}{l}\text { Hospice (1), } \\
(n=109)\end{array}$} & \multicolumn{3}{|c|}{$\begin{array}{l}\text { Hospital + LCP (2) } \\
(n=78)\end{array}$} & \multicolumn{3}{|c|}{$\begin{array}{l}\text { Hospital - LCP (3), } \\
(n=68)\end{array}$} & \\
\hline$n$ & $\%$ & $95 \% \mathrm{Cl}$ & $n$ & $\%$ & $95 \% \mathrm{Cl}$ & $n$ & $\%$ & $95 \% \mathrm{Cl}$ & $P$-value ${ }^{b}$ \\
\hline
\end{tabular}

In your opinion, during the last 2 days, did she/he appear to be in pain? (missing $n=2,0.8 \%$ )

\begin{tabular}{|l|r|r|r|r|r|r|r|r|r|r|r|}
\hline Yes, all of the time & 9 & 8.3 & $4.2-14.5$ & 6 & 7.7 & $3.3-15.2$ & 10 & 14.7 & $7.8-24.5$ \\
Yes, some of the time & 44 & 40.4 & $31.5-49.7$ & 41 & 52.6 & $41.6-63.4$ & 26 & 38.2 & $27.4-50.1$ \\
No, she/he did not appear to be in pain & 54 & 49.5 & $40.3-58.8$ & 31 & 39.7 & $29.4-50.8$ & 32 & 41.7 & $35.5-58.8$ \\
\hline
\end{tabular}

In your view, did the doctors and nurses do enough to help relieve the pain? (missing $n=5,2.0 \%$ )

\begin{tabular}{|c|c|c|c|c|c|c|c|c|c|c|}
\hline Yes, all of the time & 78 & 72.2 & $62.6-79.4^{*}$ & 46 & 59.0 & $47.9-69.4^{\star \star}$ & 23 & 33.8 & $23.4-45.6$ & $<0.0001$ \\
\hline Yes, some of the time & 8 & 7.4 & $3.5-13.4^{*}$ & 13 & 16.7 & $9.7-26.1$ & 18 & 26.5 & $17.1-37.8$ & \\
\hline No, not at all & 0 & 0.0 & $0.0-2.3^{*}$ & 3 & 3.8 & $1.1-9.9$ & 7 & 10.3 & $4.7-19.2$ & \\
\hline Not applicable, she/he was not in pain & 21 & 19.4 & $12.7-27.4$ & 14 & 17.9 & $10.7-27.6$ & 19 & 27.9 & $18.4-39.4$ & \\
\hline
\end{tabular}

In your opinion, during the last 2 days, did she/he appear restless? (missing $n=5,2.0 \%$ )

\begin{tabular}{|l|r|r|r|r|r|r|r|r|r|r|r|}
\hline Yes, all of the time & 8 & 7.3 & $3.5-13.4 *$ & 7 & 9.0 & $4.1-16.8$ & 17 & 25.0 & $15.9-36.2$ & $<0.0001$ \\
Yes, some of the time & 52 & 47.7 & $38.5-57.0$ & 35 & 44.9 & $34.2-55.9$ & 38 & 55.9 & $44.0-67.2$ & \\
No, she/he did not appear to be restless & 46 & 42.2 & $33.2-51.6 *$ & 35 & 44.9 & $34.2-55.9 * \star$ & 12 & 17.6 & $10.0-28.0$ &
\end{tabular}

In your view, should more have been done by the doctors and nurses to help relieve his/her restlessness? (missing $n=14,5.5 \%$ )

\begin{tabular}{|c|c|c|c|c|c|c|c|c|c|c|}
\hline Yes & 11 & 10.2 & $5.5-16.8^{*}$ & 15 & 19.5 & $11.7-29.0$ & 27 & 39.7 & $28.7-51.6$ & $<0.0001$ \\
\hline No & 50 & 46.3 & $36.7-55.2$ & 30 & 39.0 & $28.2-49.5$ & 26 & 38.2 & $27.4-50.1$ & \\
\hline Not applicable, she/he was not restless & 42 & 38.9 & $29.8-47.9$ & 29 & 37.7 & $27.1-48.2^{\star \star}$ & 11 & 16.2 & $8.9-26.3$ & \\
\hline
\end{tabular}

In your opinion, during the last 2 days, did she/he appear to have a 'noisy rattle' to his/her breathing? (missing $n=10,3.9 \%$ )

\begin{tabular}{|l|l|l|l|l|l|l|l|r|r|}
\hline Yes, all of the time & 22 & 20.2 & $13.5-28.4^{*}$ & 10 & 12.8 & $6.8-21.6$ & 2 & 2.9 & $0.6-9.1$ \\
Yes, some of the time & 41 & 37.6 & $28.9-46.9$ & 30 & 38.5 & $28.2-49.5$ & 33 & 48.5 & $36.9-60.3$ \\
No, she/he did not appear to have a 'noisy rattle' to the breathing & 43 & 39.4 & $30.7-48.8$ & 35 & 44.8 & $34.2-55.9$ & 29 & 42.6 & $31.4-54.5$
\end{tabular}

Should more have been done to relieve the 'noisy rattle'? (missing $n=27,10.6 \%$ )

\begin{tabular}{|c|c|c|c|c|c|c|c|c|c|}
\hline Yes & 18 & 16.5 & $10.5-24.3$ & 12 & 15.4 & $8.7-24.6$ & 11 & 16.2 & $8.9-26.3$ \\
\hline No & 42 & 38.5 & $29.8-47.9$ & 23 & 29.5 & $20.3-40.1$ & 19 & 27.9 & $18.4-39.4$ \\
\hline Not applicable, there was no 'noisy rattle' to his/her breathing & 39 & 35.8 & $27.3-45.1$ & 35 & 44.9 & $34.2-55.9$ & 29 & 42.6 & $31.4-54.5$ \\
\hline
\end{tabular}

In your opinion, during the last 2 days, did she/he appear breathlessness? (missing $n=8,3.1 \%$ )

\begin{tabular}{|l|l|l|l|l|l|l|l|l|l|l|l}
\hline Yes, all of the time & 16 & 14.7 & $9.0-22.2$ & 11 & 14.1 & $7.7-23.1$ & 21 & 30.9 & $20.9-42.5$ & 0.0006 \\
Yes, some of the time & 35 & 32.1 & $23.9-41.3$ & 24 & 30.8 & $21.4-41.6$ & 28 & 41.2 & $30.1-53.0$ & & \\
No, she/he did not appear breathless & 54 & 49.5 & $40.3-58.8^{\star}$ & 40 & 51.3 & $40.3-62.2^{\star \star}$ & 18 & 26.5 & $17.1-37.8$ & &
\end{tabular}

In your view, should more have been done to help relieve the breathlessness? (missing $n=27,10.6 \%$ )

\begin{tabular}{|l|r|r|r|r|r|r|r|r|r|r|} 
Yes & 6 & 5.6 & $2.3-11.0^{\star}$ & 11 & 14.1 & $7.7-23.1$ & 16 & 23.5 & $14.7-34.6$ & $<0.0001$ \\
No & 35 & 32.4 & $23.9-41.3$ & 20 & 25.6 & $17.0-36.1$ & 28 & 41.2 & $30.1-53.0$ & \\
Not applicable, she/he was not breathless & 55 & 50.9 & $41.2-59.7$ & 40 & 51.3 & $40.3-62.2 \star \star$ & 17 & 25.0 & $15.9-36.2$ & \\
\hline
\end{tabular}

Abbreviations: $\mathrm{Cl}=$ confidence interval; $\mathrm{LCP}=$ Liverpool Care Pathway for the Dying Patient.

${ }^{\text {a }}$ Confidence intervals with * indicate significant differences between columns 1 and 3 ; confidence intervals with ** indicate significant differences between columns 2 and 3 ; percentages do not always add up to $100 \%$ due to missing responses (total number of missing responses stated within table).

${ }^{\mathbf{b}}$ Comparisons between groups were conducted using $\chi^{2}$ testing and additional testing using the Cochran-Mantel-Haenszel test if question had ordinal response options. Bold values indicate the statistically significant results.

whereas for others, including aspects of communication, more is required to be done to try to attain the hospice standard of care.

The main limitation of the study is the response rate of $35.1 \%$, which is comparatively low and lower than the $40 \%$ response rate we had estimated. This can lead to the introduction of nonresponse bias and limit the generalisability of the findings to the whole population. Post-bereavement research studies represent a difficult and sensitive area of work, and this is likely to be the main and most important reason for the low response rate. There was almost a $10 \%$ difference in the response rate between the two health-care settings, with a greater response from hospice participants. This may be related to the differing settings for the two institutions, that is, urban area for acute hospital and more affluent 'conservation' area for the hospice; a higher degree of altruism towards the hospice (which is a recognised charity); or that those who had a more positive experience were more motivated to provide feedback about the care. Our response rate is comparable with two other recent UK studies using postbereavement questionnaires (NHS Lothian, 2007; Young et al, 2008). The response rate, however, is lower than the recent UK National VOICES Bereavement Survey (response rate of $45.7 \%$ ) (Department of Health, 2012b), although this survey had three 
Table 3. Communication with the health-care team (HCT) and overall impressions: comparison of bereaved relatives' views in the hospice as opposed to the hospital ${ }^{\mathrm{a}}$

Hospice (1), ( $n=109)$

Hospital + LCP (2), $(n=78) \quad$ Hospital - LCP (3), $(n=68)$

\begin{tabular}{|l|l|l|l|l|l|l|l|l|l}
$\mathrm{n}$ & $\%$ & $95 \% \mathrm{Cl}$ & $n$ & $\%$ & $95 \% \mathrm{Cl}$ & $n$ & $\%$ & $95 \% \mathrm{Cl}$ & $P$-value \\
\hline
\end{tabular}

Did any of the doctors or nurses discuss with you the appropriateness of giving fluids through a 'drip' in the last 2 days of life? (missing $n=13,5.1 \%$ )

\begin{tabular}{l|r|r|r|r|r|r|r|r|r|r|r|r|r|r|}
\hline Yes & 29 & 26.6 & $19.0-35.4$ & 22 & 29.3 & $19.1-38.9$ & 16 & 25.0 & $14.7-34.6$ & NS \\
No & 66 & 60.6 & $51.2-69.4$ & 47 & 62.7 & $49.2-70.6$ & 46 & 71.9 & $56.0-77.9$ \\
Do not know & 8 & 7.3 & $3.5-13.4$ & 6 & 8.0 & $3.3-15.2$ & 2 & 3.1 & $0.6-9.1$ &
\end{tabular}

$3.5-13.4$

$3.3-15.2$

$0.6-9.1$

If no: would these types of discussion have been helpful? (missing $n=19,7.5 \%$ )

\begin{tabular}{|c|c|c|c|c|c|c|c|c|c|c|}
\hline Yes & 20 & 18.3 & $12.0-26.4^{*, \dagger}$ & 33 & 42.3 & $31.8-53.4$ & 33 & 48.5 & $36.9-60.3$ & 0.003 \\
\hline No & 35 & 32.1 & $23.9-41.3^{*}$ & 11 & 14.1 & 7.7-23.1 & 8 & 11.8 & $5.7-21.0$ & \\
\hline
\end{tabular}

Before she/he died, were you told she/he was likely to die? (missing $n=11,4.3 \%$ )

\begin{tabular}{|c|c|c|c|c|c|c|c|c|c|c|}
\hline $\begin{array}{l}\text { Yes } \\
\text { No }\end{array}$ & $\begin{array}{l}83 \\
20\end{array}$ & $\begin{array}{l}76.1 \\
18.5\end{array}$ & $\begin{array}{l}67.5-83.4 \\
12.0-26.4\end{array}$ & $\begin{array}{l}61 \\
13\end{array}$ & $\begin{array}{l}78.2 \\
16.7\end{array}$ & $\begin{array}{r}68.1-86.2 \\
9.7-26.1\end{array}$ & $\begin{array}{l}46 \\
21\end{array}$ & $\begin{array}{l}67.6 \\
30.9\end{array}$ & $\begin{array}{l}56.0-77.9 \\
20.9-42.5\end{array}$ & NS \\
\hline \multicolumn{11}{|c|}{ Was it the first time you were aware she/he was dying? (NA response $n=43,19.9 \% ;$ missing $n=18,7.1 \%$ ) } \\
\hline $\begin{array}{l}\text { Yes } \\
\text { No } \\
\text { Do not know }\end{array}$ & $\begin{array}{r}10 \\
66 \\
2\end{array}$ & $\begin{array}{r}12.2 \\
80.5 \\
2.4\end{array}$ & $\begin{array}{l}6.4-20.3^{\dagger, \star} \\
69.9-87.1^{\dagger, *} \\
0.5-7.5\end{array}$ & $\begin{array}{r}26 \\
33 \\
0\end{array}$ & $\begin{array}{r}42.6 \\
54.1 \\
0.0\end{array}$ & $\begin{array}{c}30.8-55.1 \\
41.7-66.2 \\
0.0-4.0\end{array}$ & $\begin{array}{r}17 \\
25 \\
2\end{array}$ & $\begin{array}{r}37.0 \\
54.3 \\
2.4\end{array}$ & $\begin{array}{r}24.1-51.4 \\
40.1-68.1 \\
0.9-13.2\end{array}$ & 0.004 \\
\hline
\end{tabular}

Did you have enough privacy when you were told? (NA response $n=46,18.0 \%$; missing $n=16,6.3 \%$ )

\begin{tabular}{|c|c|c|c|c|c|c|c|c|c|c|}
\hline Yes & 74 & 89.2 & $81.2-94.5$ & 49 & 80.3 & $69.1-88.8$ & 37 & 80.4 & $67.3-89.9$ & NS \\
\hline No & 3 & 3.6 & $1.0-9.3$ & 8 & 13.1 & $6.4-23.2$ & 7 & 15.2 & $7.1-27.6$ & \\
\hline Do not know & 2 & 2.4 & $0.5-7.5$ & 2 & 3.3 & $0.7-10.1$ & 0 & 0.0 & $0.0-5.3$ & \\
\hline
\end{tabular}

Were you told in a sensitive manner? (NA response $n=46,18.0 \%$; missing $n=23,9.0 \%$ )

\begin{tabular}{|c|c|c|c|c|c|c|c|c|c|}
\hline Yes & 75 & 90.4 & & 53 & 86.9 & 76.8-93.6 & 40 & $\begin{array}{r}86.9 \\
6.5\end{array}$ & $\begin{array}{r}75.1-94.4 \\
19-16.4\end{array}$ \\
\hline No & 0 & 0.0 & $0.0-3.0$ & 4 & 6.6 & $2.3-14.8$ & 3 & 6.5 & $1.9-16.4$ \\
\hline
\end{tabular}

Did a member of the HCT talk to you about what would happen at the time of his/her death? (missing $n=10$ )

\begin{tabular}{|l|l|l|l|l|l|l|l|l|r|r|r|r} 
Yes & 44 & 40.4 & $* 31.5-49.7$ & 22 & 28.8 & $19.1-38.9$ & 11 & 16.2 & $8.9-26.3$ & 0.002 \\
No & 61 & 56.0 & $* 46.6-65.0$ & 52 & 66.7 & $55.8-76.4$ & 55 & 80.9 & $70.4-88.8$ &
\end{tabular}

If no: would this type of discussion have been useful? (NA response $n=69,3.9 \%$; missing $n=21,8.2 \%$ )

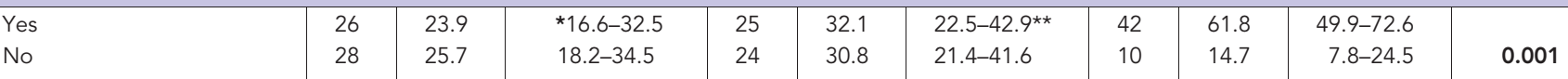

How much of the time was she/he treated with dignity and respect by the HCT? (missing $n=2,0.8 \%$ )

\begin{tabular}{|c|c|c|c|c|c|c|c|c|c|c|}
\hline Always & 97 & 89.0 & $82.1-93.8^{\dagger, \star}$ & 45 & 57.7 & $46.6-68.2$ & 29 & 42.6 & $31.4-54.4$ & $<0.0001$ \\
\hline Most of the time & 11 & 10.1 & $5.5-16.8^{\dagger, *}$ & 24 & 30.8 & $21.4-41.6$ & 24 & 35.3 & $27.7-47.1$ & \\
\hline Some of the time/never & 0 & 0.0 & $0.0-2.3^{\dagger, \star}$ & 8 & 10.3 & $5.0-18.4$ & 13 & 19.1 & $11.2-29.6$ & \\
\hline Do not know & 0 & 0.0 & $0.0-2.3$ & 1 & 1.3 & $0.1-5.8$ & 1 & 1.5 & $0.2-6.7$ & \\
\hline
\end{tabular}

Overall, in your opinion, were you adequately supported by the НСT? (missing $n=20,7.8 \%$ )

\begin{tabular}{|l|r|r|r|r|r|r|r|r|r|r|r|}
\hline Yes & 95 & 88.0 & $79.9-92.4^{\dagger * *}$ & 52 & 67.5 & $55.8-76.4$ & 35 & 52.2 & $39.7-63.1$ & $<0.0001$ \\
No & 7 & 6.5 & $2.9-12.2^{\dagger, *}$ & 19 & 24.7 & $15.9-34.7$ & 27 & 40.3 & $28.7-51.5$ & & 27 \\
\hline
\end{tabular}

Abbreviations: $\mathrm{Cl}=$ confidence interval; $\mathrm{LCP}=$ Liverpool Care Pathway for the Dying Patient.

${ }^{a}$ Confidence intervals with ${ }^{\dagger}$ indicate significant differences between columns 1 and 2 ; confidence intervals with * indicate significant differences between columns 1 and 3 ; confidence intervals with ${ }^{* \star}$ indicate significant differences between columns 2 and 3 ; percentages do not always add up to $100 \%$ due to missing responses (total number of missing responses stated within table). ${ }^{\mathbf{b}}$ Comparisons between groups were conducted using $\chi^{2}$ testing and additional testing using the Cochran-Mantel-Haenszel test if question had ordinal response options. Bold values indicate the statistically significant results.

mail-outs, a practice which was not permitted by our ethical committee. Overall, our participants were similar to our nonparticipant group, with the exception that non-participants were more likely to have 'other (for example, unknown primary)' as their primary site of cancer. We do not have, however, information on other demographic factors known to influence response rates, therefore, caution is needed about the generalisability of our results. The second limitation of this study is the difficulty in clarifying the sole extent to which the LCP influenced perceptions and the role of other factors, such as communication skills teaching and the HSPCT. In part, this relates to only have single study sites for the hospice and hospital, and potentially to our sample size. As most of our analysis compares three groups, our study may have been underpowered (ideally we should have obtained 100 


\begin{tabular}{|c|c|c|}
\hline Independent item & $\operatorname{Exp}(\mathrm{B})(95 \% \mathrm{Cl})^{\mathrm{a}}$ & $P$-value \\
\hline \multicolumn{3}{|l|}{ Place of care } \\
\hline $\begin{array}{l}\text { Hospital } \\
\text { Hospice } \\
\text { Patient age } \\
\text { Patient gender }\end{array}$ & $\begin{array}{l}8.46(4.19-17.10) \\
0.99(0.98-1.02) \\
0.83(0.49-1.41)\end{array}$ & $\begin{array}{l}\text { Ref. cat. } \\
<0.0001 \\
0.84 \\
0.50\end{array}$ \\
\hline \multicolumn{3}{|l|}{ Patient diagnosis } \\
\hline $\begin{array}{l}\text { Others } \\
\text { Lung } \\
\text { Prostate } \\
\text { Colorectal } \\
\text { Oesophagus } \\
\text { Stomach } \\
\text { Bladder } \\
\text { Pancreas } \\
\text { Leukaemia } \\
\text { NHL } \\
\text { Breast } \\
\text { Ovary }\end{array}$ & $\begin{array}{c}\text { Ref. cat. } \\
0.85(0.38-1.88) \\
0.75(0.23-2.38) \\
3.43(0.91-13.0) \\
6.71(0.82-54.99) \\
0.63(0.17-2.26) \\
0.67(0.17-2.69) \\
0.38(0.14-1.01) \\
0.54(0.14-2.00) \\
0.67(0.10-4.39) \\
1.34(0.36-4.77) \\
0.60(0.12-2.96)\end{array}$ & $\begin{array}{l}0.17 \\
0.69 \\
0.62 \\
0.07 \\
0.08 \\
0.47 \\
0.57 \\
0.06 \\
0.36 \\
0.68 \\
0.65 \\
0.53\end{array}$ \\
\hline \multicolumn{3}{|l|}{ Care supported by LCP } \\
\hline $\begin{array}{l}\text { Hospital without LCP } \\
\text { Hospital with LCP } \\
\text { Patient age } \\
\text { Median time since bereavement } \\
\text { HSPCT involvement }\end{array}$ & $\begin{array}{l}1.80(0.92-3.49) \\
1.01(0.98-1.04) \\
1.00(0.99-1.00) \\
0.96(0.49-1.87)\end{array}$ & $\begin{array}{l}\text { Ref. cat. } \\
0.09 \\
0.51 \\
0.61 \\
0.89\end{array}$ \\
\hline $\begin{array}{l}\text { Abbreviations: } \mathrm{Cl}=\text { confidence interval; } \\
\mathrm{LCP}=\text { Liverpool Care Pathway for the } \mathrm{D} \\
\mathrm{a}_{\text {Exp }}(\mathrm{B}) \text { or exponential of the beta repre } \\
\text { dependant variable (whether participar } \\
\text { team) and the independent variables (pa } \\
\text { statistically significant results. }\end{array}$ & $\begin{array}{l}{ }^{\mathrm{CT}}=\text { hospital specialist } \mathrm{p} \\
\text { Patient. } \\
\mathrm{s} \text { the odds ratio of the asso } \\
\text { as adequately supported } \\
\text { demographic details). Bolc }\end{array}$ & $\begin{array}{l}\text { ative care tean } \\
\text { ion between th } \\
\text { the health-car } \\
\text { lues indicate th }\end{array}$ \\
\hline
\end{tabular}

participants for each group). The 'Hospital with LCP' participants more frequently had involvement from the HSPCT, which is likely to have had a positive impact on the perceptions of care. A previous systematic review assessing the effect of specialist palliative care teams (both hospital and community) showed benefit in terms of satisfaction with care and symptom control (Hearn and Higginson, 1998). Additionally, a further review specifically of hospital teams showed small positive benefits, although limitations in the study design affected assessment (Higginson et al, 2002). The HSPCT within our study hospital was established in 1994, limiting the potential time-lag benefit, but clarifying the extent of the involvement of the HSPCT on both hospital groups, would be useful. Our choice of study groups would also influence this and may have introduced selection bias. Ideally, we would have liked to also have had a 'Hospice without LCP' group and be certain that the 'Hospital without LCP' group was a representative group, that is, that the death was expected and care could have, and potentially should have, been supported by the LCP. The third limitation relates to the fact that the bereaved relatives' views cannot be assumed to be the same as that of the deceased patient. Post-bereavement studies, however, have certain advantages: they can reflect care for all those who have died rather than just those who are well enough to participate; and they provide additional information about the participants' own experience, as well as provide 'proxy' information about patient care (Fowler et al, 1999).

One of the strengths of this study is the specific detail obtained, thus providing a comprehensive picture about care for the dying
Table 5. Univariate analysis of demographic details predicting likelihood of participants perceiving themselves to be adequately supported by health-care team

\begin{tabular}{|l|c|c|}
\hline Independent item & $\operatorname{Exp}(\mathrm{B})(95 \% \mathrm{Cl})^{\mathrm{a}}$ & $P$-value \\
\hline Place of care & Ref. cat. & \\
\hline Hospital & $7.18(3.08-16.73)$ & $<0.0001$ \\
Hospice & $0.99(0.96-1.01)$ & 0.31 \\
Patient age & $0.97(0.53-1.80)$ & 0.93 \\
Patient gender
\end{tabular}

\section{Patient diagnosis}

\begin{tabular}{|l|l|l|}
\hline Others & Ref. cat. & 0.84 \\
Lung & $0.99(0.39-2.50)$ & 0.98 \\
Prostate & $0.71(0.19-2.69)$ & 0.62 \\
Colorectal & $1.57(0.45-5.45)$ & 0.48 \\
Oesophagus & $1.57(0.31-8.08)$ & 0.59 \\
Stomach & $2.57(0.30-22.37)$ & 0.39 \\
Bladder & $1.14(0.21-6.11)$ & 0.88 \\
Pancreas & $0.46(0.16-1.38)$ & 0.17 \\
Leukaemia & $0.67(0.15-2.98)$ & 0.60 \\
NHL & $0.43(0.06-2.87)$ & 0.38 \\
Breast & $1.24(0.30-5.07)$ & 0.77 \\
Ovary & $1.71(0.19-15.66)$ & 0.63
\end{tabular}

\section{Care supported by LCP}

Hospital without LCP

Hospital with LCP

Patient age

Median time since bereavement

HSPCT involvement

\begin{tabular}{c|c} 
Ref. cat. & \\
$2.11(1.02-4.37)$ & 0.04 \\
$1.0(0.97-1.03)$ & 0.99 \\
$1.0(0.99-1.00)$ & 0.53 \\
$2.21(1.02-4.76)$ & 0.04
\end{tabular}

Abbreviations: $\mathrm{Cl}=$ confidence interval; $\mathrm{HSPCT}=$ hospital specialist palliative care team $\mathrm{LCP}=$ Liverpool Care Pathway for the Dying Patient.

${ }^{a} \operatorname{Exp}(B)$ or exponential of the beta represents the odds ratio of the association between the dependant variable (whether participant was adequately supported by the health-care team) and the independent variables (patient demographic details). Bold values indicate the statistically significant results.

cancer patients and identifying the areas that require improvement. Although aspects of communication were of a similar quality in both health-care settings, there was still unmet need for information about the provision and withdrawal of fluids and what to expect when someone dies, with the greatest degree of unmet need seen for the 'Hospital without LCP' participants. Adequate control of distressing symptoms in the last days of life is a key component of good care. Hospice and 'Hospital with LCP' participants reported very similar symptom prevalence and with the exception of retained respiratory tract secretions, reported a lower symptom burden compared with the 'Hospital without LCP' participants. These findings may be related to a genuine difference in symptom prevalence, with patients from the 'Hospital without LCP' group having more complex symptoms. Alternatively, this could indicate that the LCP is encouraging a more intensive and pro-active approach to symptom control, which would be in keeping with the findings from a Scottish study undertaken in eight care homes using the LCP (Hockley et al, 2005), and a North American study that used the 'Palliative Care for Advanced Disease' integrated pathway in the last days of life (Bookbinder et al, 2005). A further consideration is the influence of the shorter time since bereavement for the 'Hospital with LCP' participants. This was mainly related to difficulties retrieving accurate next-ofkin details for the 'Hospital without LCP' group (more likely to be missing or incomplete), which required retrieval of the medical case notes. Perceptions about quality of care over time can change, with pain and depression tending to be reported as less frequent and severe as time passes (McPherson and Addington-Hall, 2004). 
If this principle was applied to our study, it would suggest an underestimation of the symptom severity within the 'Hospital without LCP' group, and that the differences may have been actually greater than our reported findings.

Further clarification about the role of other external influencing factors is merited by assessing quality of care for the dying in the institutions that use an integrated care pathway with comparable ones, which do not. Since this study has been conducted, version 12 of the LCP has been launched (Ellershaw and Wilkinson, 2011 b), with more detailed documentation about the decisions relating to clinically assisted hydration and nutrition. Further evaluation of the impact of these changes is required, ideally by using a before- and after-study approach. Additionally, in order to clarify whether it is simply the bereaved relatives' perceptions that are altered or whether there is a significant change in clinical practice when the LCP is used to support care, an observational study would be beneficial. Although our results suggest that there has been some improvement in care for dying cancer patients within the hospital when the LCP is used, further progress is needed to be able to deliver care, which is more comparable with the hospice standard. Ongoing review and updating of the LCP as well as educational initiatives focusing on pertinent end-of-life discussions would be practical ways to facilitate this, and to hopefully further improve the experience of the dying patients and their families in the hospital sector.

\section{ACKNOWLEDGEMENTS}

We wish to thank all the bereaved relatives who participated in this study.

\section{REFERENCES}

Addington-Hall JM, O'Callaghan AC (2009) A comparison of the quality of care provided to cancer patients in the UK in the last three months of life in in-patient hospices compared with hospitals, from the perspective of bereaved relatives: results from a survey using the VOICES questionnaire. Palliat Med 23(3): 190-197.

Auret K, Bulsara C, Joske D (2003) Australasian haematologist referral patterns to palliative care: lack of consensus on when and why. Intern Med J 33: 190-197.

Bookbinder M, Blank A, Arney E, Wollner D, Lesage P, McHugh M, Indelicato RA, Harding S, Barenboim A, Mirozyev T, Portenoy RK (2005) Improving end-of-life care: development and pilot-test of a clinical pathway. J Pain Symptom Manage 29: 529-543.

Clerk JB, Sheward K, Marshall B, Allan SG (2012) Staff perceptions of end-oflife care following implementation of the Liverpool Care Pathway for the Dying Patient in the acute care setting: a New Zealand perspective J Palliat Med 15(4): 468-473.

Commonwealth of Australia (2010) Supporting Australians to live well at the end of life. National Palliative Care Strategy 2010.

Costantini M, Balzib D, Garronecc E, Orlandinib C, Parodic S, Vercellic M, Bruzzi P (2000) Geographical variations in place of death among Italian communities suggest an inappropriate hospital use in the terminal phase of cancer disease. Public Health 114: 15-20.

Department of Health (2008a) End of Life Care Strategy. Promoting High Quality Care for all Adults at the End of Life. Department of Health: London.

Department of Health (2012b) First National VOICES Survey of Bereaved People: Key Findings Report. Department of Health: London.
Dunlop RJ, Davies RJ, Hockley JM (1989) Preferred $v s$ actual place of death: a hospital palliative care support team experience. Palliat Med 3(3): 197-201.

Ellershaw JE, Foster A, Murphy D, Shea T, Overill S (1997a) Developing an integrated care pathway for the dying patient. Eur J Palliat Care 4(6): 203-207.

Ellershaw JE, Wilkinson S (2011b) Care of the dying. A Pathway to Excellence. 2nd edn (Oxford University Press: Oxford.

Field D (1989) Nursing the Dying. Routledge: London.

Fowler FJ, Coppola KM, Teno JM (1999) Methodological challenges for measuring quality of care at the end of life. J Pain Symptom Manage 17(2): 114-119.

General Medical Council (2010) Treatment and care towards the end of life: good practice in decision-making.

Gomes B, Calanzani N, Higginson IJ (2011a) Reversal of the British trends in place of death: time series analysis 2004-2010. Palliat Med 26(2): 102-107.

Gomes B, Higginson IJ (2008b) Where people die (1974-2030): past trends, future projections and implications for care. Palliat Med 22: 33-41.

Hearn J, Higginson I (1998) Do specialist palliative care teams improve outcomes for cancer patients? A systematic literature review. Palliat Med 12: $317-332$.

Higginson IJ, Finlay I, Goodwin DM, Cook AM, Hood K, Edwards AG, Douglas HR, Norman CE (2002) Do hospital-based palliative teams improve care for patients and families at the end of life? J Pain Symptom Manage 23(2): 96-106.

Hockley J, Dewar B, Watson J (2005) Promoting end-of-life care in nursing homes using an 'integrated care pathway for the last days of life'. J Res Nurs 10(2): 135-152.

Jack BA, Gambles M, Murphy D, Ellershaw J (2003) Nurses' perceptions of the Liverpool Care Pathway for the dying patient in the acute hospital setting. Int J Palliat Nurs 9(9): 375-381.

Mayland CR (2010) 'Evaluating Care and Health Outcomes - for the Dying' (ECHO-D): an instrument to assess quality of care and the impact of the Liverpool Care Pathway for the Dying Patient. Doctor of Medicine Thesis. University of Liverpool.

Mayland CR, Williams EMI, Ellershaw JE (2012b) Assessing quality of care for the dying: the development and initial validation of a postal self-completion questionnaire for bereaved relatives. Palliat Med 26(7): 897-907.

McPherson CJ, Addington-Hall JM (2004) Evaluating palliative care: bereaved family members' evaluations of patients' pain, anxiety and depression. J Pain Symptom Manage 28(2): 104-114.

Mills M, Davies HTO, Macrae WA (1994) Care of dying patients in hospital. Br Med J 309: 583-586.

National End of Life Care Programme (2010) The route to success in end of life care - achieving quality in acute hospitals.

NHS Lothian (2007) Lothian VOICES: views of informal carers on end of life cancer care in Lothian.

Veerbeek L, Zuylen LV, Swart SJ, van der Maas P, de-Vogel-Voogt E, van der Rijt CCD, van der Heide A (2008) The effect of the Liverpool Care Pathway for the dying: a multi-centre study. Palliat Med 22: $145-151$.

Yang L, Sakamoto N, Marui E (2006) A study of home deaths from 1951 to 2002. BMC Palliat Care 5: 2.

Young AJ, Rogers A, Addington-Hall J (2008) The quality and adequacy of care received at home in the last 3 months of life by people who died following a stroke: a retrospective study of surviving family and friends using the Views of Informal Carers Evaluation of Services questionnaire. Health Soc Care Community 16(4): 419-428.

This work is published under the standard license to publish agreement. After 12 months the work will become freely available and the license terms will switch to a Creative Commons AttributionNonCommercial-Share Alike 3.0 Unported License.

Supplementary Information accompanies this paper on British Journal of Cancer website (http://www.nature.com/bjc) 